\title{
Discrimination, HIV Conspiracy Theories and Pre-Exposure Prophylaxis Acceptability in Gay Men
}

\author{
Daniel Jolley \\ Northumbria University, UK \\ Rusi Jaspal \\ Nottingham Trent University, UK
}

\begin{abstract}
Background: Combination prevention, which includes PrEP, is essential for achieving the zero HIV infections target in the UK by 2030. It is important to assess attitudes towards PrEP in at risk-populations. This study focuses on the impact of discrimination and HIV conspiracy theorising on attitudes towards PrEP in gay men in the UK.

Methods: 244 White British gay men completed a survey that included demographic questions, and measures of sexual health screening, hypervigilance, sexual orientation discrimination, quality of contact with healthcare professionals, belief in conspiracy theories, and attitudes towards PrEP. Data were analysed using multiple linear regression and mediation analysis.

Results: Discrimination was positively correlated with HIV conspiracy beliefs and negatively correlated with PrEP acceptance. Mediation analyses demonstrated that the relationship between discrimination and attitudes towards PrEP was explained by HIV conspiracy theorising. Gay men who had attended a sexual health screening (vs. never attended) reported higher belief in HIV conspiracy theories. A further mediation analysis showed that reported poor contact with a healthcare professional was associated with an increased belief in HIV conspiracy theories, which was associated with negative attitudes towards PrEP. Both perceived discrimination and poor contact with a healthcare professional were exacerbated by hypervigilance.

Conclusions: HIV conspiracy theorising is an important variable in understanding attitudes towards PrEP among gay men. Its roots are in adverse social experiences (e.g. discrimination, poor contact with healthcare professionals) and its consequences may be the rejection of PrEP. HIV prevention and PrEP campaigns must focus on prejudice reduction and challenging conspiracy beliefs.
\end{abstract}

Keywords: Discrimination; conspiracy theories; HIV; gay men; PrEP

\section{Citing this article}

Jolley, D., \& Jaspal, R. (2020). Discrimination, HIV conspiracy theories \& PrEP acceptability in gay men. Sexual Health. https://doi.org/10.1071/SH20154 


\section{Discrimination, HIV Conspiracy Theories and Pre-Exposure Prophylaxis Acceptability in Gay Men}

Between 2012 and 2018, HIV incidence in gay, bisexual and other men who have sex with men (MSM) in the UK decreased by $71 \%^{[1]}$. There is now an ambitious, but achievable, target to end all HIV transmissions in the UK by 2030. 'Combination prevention', which includes condoms, alongside increased HIV testing, Treatment as Prevention (TasP), and Pre-Exposure Prophylaxis (PrEP), is key ${ }^{[2]}$. In early 2020, the UK government pledged funding to make PrEP available to patients free of charge on the National Health Service (NHS), although details of eligibility have not yet been clarified ${ }^{[3]}$. PrEP is recommended for MSM who are HIV-negative, have had condomless anal sex in the last three months and believe that it is likely that they will have condomless sex again in the next three months ${ }^{[4]}$. However, not all individuals, including gay men, who could benefit from PrEP because they do not consistently use other risk reduction strategies (e.g., condoms), endorse PrEP for their own use. This can be attributed to decreased access, cost, fear of side effects, perceived drug inefficacy, and discrimination ${ }^{[5]}$. It is vital to understand PrEP acceptability if its full potential is to be achieved.

This study focuses on the role of a novel variable in research into PrEP acceptability conspiracy theorising. Irrational beliefs and cognitive biases, such as conspiracy theorising, can inhibit both healthcare engagement and HIV prevention efforts. Belief in conspiracy theories may arise from experiences of discrimination (as these experiences highlight previous unfair treatment of one's social group ${ }^{[6]}$ ), and undermine trust in authority, including healthcare practitioners ${ }^{[7,8]}$. As a stigmatised minority, gay men may be more prone to conspiracy theorising than the general population. They are also at a higher risk of HIV. This study examines the impact of conspiracy theorising on the acceptability of PrEP, a clinically effective HIV prevention tool, among gay men in the UK.

\section{Gay men and HIV risk}

Despite increasing levels of HIV awareness in this population, many gay men continue to engage in behaviours that put them at risk of infection, and have poorer health outcomes due to delayed diagnosis ${ }^{[9]}$. The motives underpinning risk behaviour are complex and include low psychological wellbeing, peer pressure, and low HIV risk perception ${ }^{[10,11,12]}$. Discrimination (especially due to valued, immutable identities, such as sexual orientation) is also a key determinant of HIV risk ${ }^{[13]}$. Gay men generally experience high levels of discrimination because of their sexual orientation ${ }^{[14]}$. Actual and anticipated discrimination in healthcare settings can lead to low-quality engagement with practitioners and to disengagement ${ }^{[15]}$. This can contribute to the risk of infection.

There is evidence of a relationship between belief in conspiracy theories, which represent HIV/AIDS as a form of genocide against minority groups, and HIV risk (both risk of infection and onward transmission). Most research into HIV conspiracy theories has focused on African Americans and, thus, the evidence in other groups (e.g., White British gay men) is limited $^{[16]}$. Among African Americans, HIV conspiracy theories appear to constitute a barrier to HIV prevention given their association with negative condom attitudes and inconsistent condom use ${ }^{[17]}$. HIV conspiracy beliefs are seen to be a form of medical mistrust - thus an individual who endorses such beliefs may be suspicious of public health recommendations by doctors regarding safe sexual practices, and treatment recommendations ${ }^{[18]}$. Moreover, a systematic review has revealed the impact of both HIV conspiracy theories and the nature of engagement with healthcare practitioners on overall healthcare engagement ${ }^{[19]}$. Research shows an impact of conspiracy theorising on antiretroviral therapy (ART) adherence, which may be attributed to the focus of HIV conspiracy theories on pharmaceutical companies ${ }^{[20]}$. A study of younger gay men living with HIV has revealed that conspiracy theorising negatively 
impacts attitudes towards medication ${ }^{[21]}$. Furthermore, in a study of HIV-positive African American gay men ${ }^{[16]}$, HIV conspiracy beliefs were associated with decreased adherence to ART. However, the role of HIV conspiracy theorising on attitudes towards PrEP, a key component of combination prevention, has received little attention. Olansky et al. ${ }^{[22]}$ do provide initial evidence in a US ethnic minority sample of MSM that HIV/AIDs conspiracy beliefs are associated with lower PrEP awareness. Moreover, Black MSM who endorsed HIV conspiracy beliefs reported a lower intention to adopt $\operatorname{PrEP}^{[23]}$. Thus, emerging research suggests that in minority groups conspiracy theorising may impact PrEP acceptability.

\section{PrEP acceptability among gay men}

PrEP acceptability varies among gay men. A recent meta-analysis ${ }^{[24]}$ exhibited an overall acceptance rate of $58.7 \%$ among gay men and, in the UK, it has been shown that $64 \%$ of HIVnegative gay men attending sexual health clinics perceived PrEP as personally beneficial ${ }^{[25]}$. Higher educational attainment is a strong proxy for PrEP endorsement among gay men - higher rates of PrEP use are observable in those achieving education to a postgraduate level or above $^{[26,27]}$. Moreover, younger gay men are more likely than older gay men to use PrEP, suggesting that attitudes are more favourable in younger men ${ }^{[28]}$. Stigma associated with PrEP, namely that it is associated with sex with multiple sexual partners and that it may be mistaken for HIV medication, also constitutes a significant barrier to acceptability and uptake, given that some gay men may fear discrimination if they use $i^{[3]}$.

Understandably, HIV testing has been found to provide a good opportunity for healthcare practitioners to explain PrEP to at-risk patients ${ }^{[24]}$. However, given previous research into the quality of contact with healthcare practitioners ${ }^{[29]}$, it could be hypothesised that the nature of one's contact with healthcare practitioners is an important determinant of attitudes towards PrEP. More specifically, a positive encounter may lead individuals to engage with the recommendations of their healthcare practitioners (which may include PrEP), while a negative encounter may lead to less engagement. Negative contact, coupled with the belief in HIV conspiracy theories, may, in turn, lead to less endorsement of practitioner recommendations.

Marginalised minority groups (e.g., gay men) may anticipate discrimination due to chronic exposure to stigma. They may be hypervigilant to discrimination and, thus, misinterpret innocuous events as discriminatory ${ }^{[30]}$. This may contribute to the perceived quality of contact with healthcare practitioners during a sexual health screening. As people from minority groups may already suffer from discrimination, and thus be more likely to distrust authorities, discrimination may increase conspiracy theorising ${ }^{[31]}$. In support of this idea, research has shown that African-Americans who believed they had been the victims of police harassment ${ }^{[32]}$ or racial discrimination ${ }^{[33]}$ were more likely to endorse conspiracy theories. Whilst conspiracy theories have been examined in minority groups, such as African Americans, there has been no research into gay men in the UK.

\section{Hypotheses}

1. Older age and lower educational attainment are associated with negative attitudes towards PrEP.

2. Experiences of discrimination are associated with conspiracy theorising, which in turn is associated with negative attitudes towards PrEP.

3. Negative contact with healthcare practitioners is associated with conspiracy theorising, which in turn is associated with negative attitudes towards PrEP.

4. Hypervigilance is associated with discrimination and negative contact, which in turn is associated with conspiracy theorising that is, then, associated with negative attitudes towards PrEP. 


\section{Ethics}

\section{Methods}

The study was conducted in accordance with the British Psychological Society Code of Ethics and Conduct, and received ethics approval from the School of Health and Life Sciences Ethics Committee at Northumbria University (ref: 21393).

\section{Participants}

Two hundred and forty-four White British gay men living in the UK were recruited from Prolific (prolific.co/), a popular online crowdsourcing platform. To be eligible for the study, participants needed to be registered on Prolific as being White, British, living in the UK, gay and male. We aimed for the participant size to approach 250 participants for stable estimates before we stopped recruitment ${ }^{[34]}$, where participants were paid 90-pence for their time (equivalent $£ 6.69$ per hour). Participants were aged between 18 and 70 years $(M=34.35$, $S D=12.04)$. Two hundred and seven $(85 \%)$ participants reported that they were HIV-negative, 10 (4\%) HIV-positive and $27(11 \%)$ indicated that they did not know their HIV status. One hundred and seventy-six (72\%) participants were never married, $26(11 \%)$ were married, less than $1 \%$ were either widowed (2), divorced (3) or separated (2) and $35(14 \%)$ would rather not say. Thirty-four (14\%) participant indicated their highest level of education was a higher degree (e.g., MSc, PhD), 112 (46\%) a degree (e.g., BA, BSc), 68 (28\%) had A levels, 25 (11\%) GCSE's and $4(2 \%)$ had other qualifications. One hundred and one (66\%) participants reported having had a sexual health screening in the past.

\section{Measures and procedure}

First, participants indicated their informed consent before beginning the questionnaire. Next, participants completed the Everyday Discrimination Scale ${ }^{[35]}(\alpha=.87)$. There were 5 statements (e.g., "You are treated with less courtesy or respect than other people"), and participants indicated the frequency of discrimination because of their sexuality on a 7-point scale $(1=$ never, $7=$ all the time). They then completed a measure of hypervigilance ${ }^{[36]}(\alpha=.87)$, where there were 5 statements (e.g., "As soon as I wake up and for the rest of the day, I am watching for signs of trouble") which were completed on a 5-point scale ( $1=$ not at all like me, $7=$ very much like me). Next, two measures of belief in conspiracy theories were completed. Belief in HIV/AIDS conspiracy theories was measured with 9 items (e.g., "HIV is a human-made virus", $\alpha=.88$, adapted from $\left.{ }^{[17[}\right)$ on a 7 -point scale $(1=$ strongly disagree, $7=$ strongly agree). Belief in general notions of a conspiracy was measured using a one-item measure ${ }^{[37]}$ ("I think that the official version of the events given by the authorities very often hides the truth") on a 7-point scale (1=completely false, $7=$ completely true). Attitudes towards $\operatorname{PrEP}^{[38]}$ were then measured with 14 items (e.g., "Gay people should take PrEP, $\alpha=0.84$ ) on a 7-point scale ( $1=$ strongly disagree, $7=$ strongly agree). Next, participants were asked if they had ever attended a sexual health screening (1=yes, $2=$ no). Participants who had attended a screening were asked to evaluate their contact with healthcare practitioners during the screening ${ }^{[39]}$. Specifically, participants were asked how often a variety of negative (3 items: "intimidated"; "ridiculed"; "made to feel unwelcome", $\alpha=.82$ ) and positive ( 3 items: "being supported"; "helped"; "befriended", $\alpha=.72$ ) experiences had occurred during the screening on a 7-point scale ( $1=$ never, $7=$ very often). All measures were counterbalanced ${ }^{1}$. Higher scores represent greater discrimination, hypervigilance, conspiracy beliefs, anti-PrEP attitudes, and reported positive and negative contact. Finally, participants completed demographic information, were debriefed, thanked and compensated for their time.

\footnotetext{
${ }^{1}$ We also included a 6-item measure of risky behaviours. However, its reliability was poor $(\alpha=.63)$ by traditional conventions (e.g., see ${ }^{[40]}$ ) so was not included in subsequent analyses.
} 


\section{Tests of normality}

\section{Results}

As belief in HIV conspiracy theories was not normally distributed, a transformed ( $\operatorname{Lg} 10)$ variable was used in the analyses. All other variables met parametric assumptions. There were no missing data.

\section{Correlations and descriptive statistics}

See Table 1 for descriptive statistics for, and correlations between, all variables.

Participants did not differ by marital status or HIV status on any of the measured variables $(p>.05)$ and, thus, these variables were not analysed further. Older participants were less supportive of PrEP and less hypervigilant. Participants who were more educated were less likely to believe HIV conspiracy theories, to engage in general conspiracy theorising, and to be more hypervigilant. More educated participants were also marginally more supportive of PrEP. These results support hypothesis 1 and, thus, age and education were controlled for in the regression and mediation analyses.

HIV conspiracy beliefs were significantly positively associated with general conspiracy theorising, discrimination, hypervigilance, and negative contact experiences with healthcare practitioners, and negatively associated with PrEP attitudes and (marginally significantly, $p=$ .051) positive contact with healthcare practitioners. General conspiracy theorising was also significantly positively associated with discrimination, hypervigilance and negatively with positive contact. Hypervigilance was significantly positively correlated with discrimination and negative contact, and negatively correlated with positive contact. Positive contact with healthcare practitioners was significantly positively correlated with PrEP attitudes, and negatively correlated with negative contact and general conspiracy theorising. Discrimination was also significantly positively correlated with negative contact.

$$
* * \text { Table } 1 * *
$$

\section{Discrimination, conspiracy beliefs and attitudes towards PrEP}

To produce a robust test of our predictions that experiences of discrimination predict conspiracy beliefs (HIV and general conspiracy theorising, respectively) and that discrimination and conspiracy beliefs predict PrEP attitudes, three multiple linear regressions were performed (see Table 2). In each analysis, the demographic variables of age and education were included as control variables. There were also no issues of multicollinearity (i.e., acceptable VIF values).

In the regression analyses that focused on conspiracy beliefs, at Step 1, education was a significant predictor of HIV conspiracy beliefs and general conspiracy theorising, respectively. Simply, more educated participants were less likely to believe in conspiracy theories. Age was a marginally significant negative predictor of general theorising, but nonsignificant for HIV conspiracy beliefs. Adding discrimination at Step 2 significantly improved the model fit, where discrimination was a significant positive predictor of both measures of conspiracy beliefs, respectively. Education remained a significant predictor and age was nonsignificant.

In the next regression focusing on attitudes towards PrEP, at Step 1, age was a significant predictor, and education was marginally significant. Older participants were less supportive of PrEP, and those who were more educated were marginally more supportive. At Step 2, age remained a significant predictor, education a marginal predictor, and discrimination was non-significant. Adding conspiracy beliefs significantly improved the model fit, where HIV conspiracy beliefs were a significant negative predictor, but general conspiracy theorising 
was non-significant. Age remained significant, but education became non-significant alongside discrimination. Our results demonstrated that higher levels of reported discrimination were a positive predictor of conspiracy beliefs (HIV and general theorising) and that HIV conspiracy beliefs are also a negative predictor of attitudes towards PrEP.

\section{$* *$ Table $2 * *$}

To test the prediction that HIV conspiracy beliefs are a mediator between discrimination and attitudes towards PrEP, a simple mediation analysis was conducted. Based on bootstrapping with 5000 resamples using PROCESS Model $4^{[41]}$, the mean estimates effect is -.05 (SE .02) with $95 \%$ confidence interval of -0.0919 to -0.0135 (see Figure 1). Consistent with hypothesis 2 , these results demonstrate that discrimination is associated with higher levels of HIV conspiracy beliefs, which in turn predicts negative attitudes towards PrEP.

$$
\text { **Figure } 1 * *
$$

\section{Contact with healthcare practitioners, conspiracy beliefs and attitudes towards PrEP}

Next, we examined how contact with healthcare practitioners during a sexual health screening may predict conspiracy beliefs and attitudes towards PrEP. First, we compared differences between participants who had attended a sexual health screening $(n=162)$ and participants who have never attended $(n=82)^{2}$, controlling for age and education, and found that attitudes towards PrEP were significantly more positive among people who had attended a sexual health screening $(M=4.89, S D=0.78)$ than those who have never attended $(M=4.61, S D=0.78), F(1$, $240)=6.566, p=.011, \eta^{2}=.03,95 \%$ CI $-0.470 /-0.061$. We also found, however, that belief in HIV conspiracy theories was significantly higher for those who attended a sexual health screening $\left(M=1.49, S D=0.74\left[L G 1 O_{M}=0.14, S D=0.17\right]\right)$ than those who had never attended $\left(M=1.34, S D=0.63\left[L G 10_{M}=0.10, S D=0.14\right]\right), F(1,240)=4.807, p=.029, \eta^{2}=.02,95 \%$ CI -0.086 / -0.005 . There was also a similar marginal difference in general conspiracy theorising-those who had attended a sexual health screening had marginally higher conspiracy theorising $(M=3.78, S D=1.67)$ than those who never attended $(M=3.46, S D=1.55), F(1,249)=2.828$, $p=.094, \eta 2=.01,95 \%$ CI $-0.789 / 0.062$.

For participants who had attended a sexual health screening $(n=162)$, we then explored whether experiences of sexual health screening were predictive of (HIV and general) conspiracy beliefs, and then whether sexual health screening experiences and conspiracy beliefs were each unique predictors of attitudes towards PrEP. Three multiple regression analyses (see Table 3) were employed where, at Step 1, background variables of age and education were included. In the regression analyses that focused on conspiracy beliefs, at Step 1, education was a significant predictor of HIV conspiracy beliefs and a marginal predictor of general theorising; age was non-significant. Adding negative and positive contact at Step 2 significantly improved the model fit predicting HIV conspiracy beliefs - negative contact was a significant predictor of HIV conspiracy beliefs, but positive contact was non-significant. Neither positive nor negative contact predicted general conspiracy theorising.

Next, focusing on attitudes towards PrEP, age was shown to be a significant predictor, but education was non-significant. At Step 2, positive contact was a significant predictor of attitudes towards PrEP, but negative contact was non-significant. Adding conspiracy beliefs significantly improved the model fit in Step 3, where HIV conspiracy beliefs were a significant negative predictor, alongside positive contact, which remained a significant predictor. Negative

\footnotetext{
2 The sexual health screening factor (attended vs. never attended) were shown to have an equal split of ages, educational backgrounds, marital and HIV statuses.
} 
contact continued to be non-significant, alongside general conspiracy theorising. Our results provide evidence that poorer contact with healthcare practitioners was a positive predictor of HIV conspiracy beliefs, and as expected, HIV conspiracy beliefs were a negative predictor of attitudes towards PrEP. As positive contact was not a predictor of HIV conspiracy beliefs and there were no effects reported with contact and general conspiracy theorising, these two factors were not analysed further.

\section{$* *$ Table $3 * *$}

To test the prediction that HIV conspiracy beliefs are a mediator between reported negative contact with healthcare practitioners and attitudes towards PrEP, a simple mediation analysis was conducted using Process Model $4^{[41]}$ with 5000 resamples. Results demonstrated HIV conspiracy beliefs acted as a significant mediator between negative contact and attitudes towards PrEP (-.05 (SE=.02), 95\% CI -0.0991 to -0.0122). Full pattern estimates are displayed in Figure 2. Consistent with hypothesis 3, the results demonstrate that negative contact is associated with higher levels of HIV conspiracy beliefs, which was shown to then predict negative attitudes towards PrEP.

$* *$ Figure $2 * *$

\section{Hypervigilance, discrimination, HIV conspiracy beliefs and attitudes towards PrEP}

We next tested for serial mediation to explore whether hypervigilance leads to the increased perception of discrimination, which is subsequently associated with HIV conspiracy beliefs and attitudes towards PrEP (see Figure 3). We used PROCESS macro (Model $6^{[41]}$ ) and, in support of hypothesis 4 , found that discrimination and HIV conspiracy beliefs mediated the effect of hypervigilance on attitudes toward PrEP (-.02 (SE=.01), 95\% CI -0.0448 to -0.044$)^{3}$. We also found this effect to be replicated where negative contact and HIV conspiracy beliefs acted as the serial mediators (-.02 (SE=.01), 95\% CI -0.0312 to -0.0020$)$.

$$
* * \text { Figure } 3 * *
$$

\section{Discussion}

Combination prevention, which includes $\mathrm{PrEP}^{[42]}$ and social and psychological interventions (e.g., changing attitudes towards condoms, changing sexual behaviours) ${ }^{[43]}$, is central to achieving the ambitious zero-infections target by 2030. Although the UK government has now pledged funding for PrEP in 2020, it is vital to understand the possible social-psychological barriers to PrEP among gay men and in other groups at risk of HIV infection. This study shows that particular subgroups of gay men face barriers and that discrimination and conspiracy theorising may be important barriers.

The results demonstrated that both older age and lower educational attainment are associated with negative attitudes towards PrEP. Yet, the HIV burden is increasing in older people and this particular population has not been the main focus of HIV prevention campaigns ${ }^{[44]}$. Older gay men have lived through earlier stages of the HIV epidemic when ART was either non-existent or only partially effective and when condom use was, thus, promoted as the only HIV prevention approach. Some may, therefore, construe PrEP as an inappropriate development in HIV prevention ${ }^{[3]}$. Furthermore, there is evidence that gay men with a lower educational attainment experience a higher HIV burden due partly to the lack of HIV

\footnotetext{
${ }^{3}$ We also tested alternative models (i.e., discrimination $->$ hypervigilance -> belief in HIV conspiracy beliefs -> PrEP attitudes), which were shown to be non-significant.
} 
knowledge and risk awareness ${ }^{[45]}$. Thus, gay men of lower educational attainment, who are also less likely to endorse PrEP, should be a focus of future HIV prevention and PrEP promotion campaigns.

This study is the first to show that experiences of discrimination (due to sexual orientation) are associated with conspiracy theorising, and that belief in HIV conspiracy theories, in turn, is associated with negative attitudes towards PrEP. It has been demonstrated that discrimination due to valued, immutable identities (such as sexual orientation) can increase HIV risk ${ }^{[10]}$. Our study clarifies this relationship by showing that discrimination may lead to the endorsement of HIV conspiracy theories, which in turn is associated with less favourable attitudes towards PrEP. Furthermore, the study confirms this relationship specifically in a healthcare setting by demonstrating that negative contact with healthcare practitioners (an adverse event which often arises from perceived discrimination ${ }^{[25]}$ ) is associated with the endorsement of HIV conspiracy theories, which in turn leads to negative attitudes towards PrEP. The impact of conspiracy theorising on PrEP endorsement may be attributed to the focus on financial collusion by the pharmaceutical industries in mainstream HIV conspiracy theories ${ }^{[16]}$.

This finding that negative contact is a key variable has important implications for healthcare provision. It has previously been found that engagement with healthcare services (e.g., HIV testing, attending a sexual health clinic) can lead to PrEP endorsement, principally because this provides an opportunity for PrEP to be explained to the patient ${ }^{[22]}$. However, this study clarifies that the nature and quality of healthcare engagement are key. More specifically, a negative encounter (e.g., discrimination, a non-gay affirmative experience) may lead to negative attitudes towards PrEP through conspiracy theorising. As a stigmatised group in society, gay men may also be hypervigilant and, thus, exhibit a cognitive bias to anticipate discrimination - even in response to innocuous events ${ }^{[26]}$. Indeed, this study shows an effect of hypervigilance on the perception of discrimination, suggesting that those who anticipate discrimination are more likely to perceive it. In short, negative contact with healthcare practitioners may lead gay male patients to believe that they cannot trust authority or those providing healthcare and they may endorse readily accessible, but maladaptive, conspiracy beliefs. This often includes the irrational belief that HIV/AIDS is a deliberate means of harming gay men. They may, therefore, reject practitioner guidance, such as PrEP use.

\section{Limitations and Future Directions}

Although the study makes an important contribution to understanding PrEP attitudes among gay men, there are some limitations. First, the cross-sectional design precludes unequivocal statements about causation (i.e., that discrimination causes conspiracy theorising which in turn causes decreased PrEP acceptability). However, the results do provide robust foundations for causal hypotheses which should be tested using an experimental design. Second, the study focuses on a White British gay male sample, which is novel as we show an effect in this population for the first time, in contrast to research into African Americans. However, other populations, such as non-gay identified MSM, ethnic minority gay men and transgender women, are at especially high risk of HIV and experience higher levels of stigma and discrimination. Therefore, this study should be replicated in these key populations. Third, replicating in other settings where PrEP is expensive, such as in the US, and ensuring there is a diverse set of ages as younger people are possibly more likely to be early adopters of new technology ${ }^{[46]}$, would also be worthwhile directions for future research. Finally, sexual risktaking in gay men was not measured effectively in this study and the study did not include a measure of actual PrEP use, or safe sex practices or sexually transmitted infection (STI) diagnoses. The latter would help illuminate the possibility of whether the association between conspiracy beliefs and clinical attendance is partly explained by higher exposure to STIs, as 
conspiracy theorising can lead to lower rates of safe sex practices. These measures should be included in future research.

\section{Conclusions}

This study shows in a sample of gay men that discrimination and negative contact with healthcare practitioners (both exacerbated by hypervigilance) may lead to a proneness to conspiracy theorising which in turn decreases the endorsement of PrEP. There are three main recommendations. First, there is a need to focus on reducing discrimination against gay men in society, not only in the interests of a more harmonious society but also because this is a key dimension of HIV prevention. Second, it is vital to ensure that effective gay-affirmative training is provided to healthcare practitioners who should be cognisant of both hypervigilance among stigmatised groups and the insidious effects of discrimination and negative healthcare encounters on health behaviours (i.e., PrEP endorsement). Third, although HIV conspiracy theories are not necessarily pervasive among gay men, they are present. To achieve the zeroinfections target by 2030, it will be necessary to try to target every individual at risk of HIV and, crucially, to challenge HIV conspiracy theorising when this is apparent. Challenging discrimination and conspiracy theorising will be key to sustaining an appropriate level of uptake of PrEP, an important component of combination prevention.

\section{Conflicts of interest}

The authors declare no conflicts of interest.

\section{Funding information}

This research did not receive any specific funding.

\section{References}

[1] O'Halloran C, Sun S, Nash S, et al. HIV in the United Kingdom: Towards Zero 2030 [Internet] $2020 \quad$ [2020 Mar 26]. Available from: https://assets.publishing.service.gov.uk/government/uploads/system/uploads/attachment_data /file/858559/HIV_in the_UK_2019 towards_zero_HIV_transmissions_by_2030.pdf

${ }^{[2]}$ Hankins CA, Zalduondo BO. Combination prevention: a deeper understanding of effective HIV prevention. AIDS. 2010;24:s70-s80.

${ }^{[3]}$ Department of Health and Social Care. HIV drug PrEP to be available across England [Internet] 2020 [2020 Mar 26]. Available from: https://www.gov.uk/government/news/hivdrug-prep-to-be-available-across-england

[4] PrEP Impact Trial. [Internet] 2020 [2020 Aug 19]. Available from: https://www.prepimpacttrial.org.uk/

[5] Jaspal R, Daramilas C. Perceptions of pre-exposure prophylaxis (PrEP) among HIVnegative and HIV-positive men who have sex with men (MSM). Cogent Med. 2016;3(1):1256850.

[6] Douglas KM, Uscinski JE, Sutton RM, Cichocka A, Nefes T, Ang CS, Deravi F. Understanding Conspiracy Theories. Political Psychology. 2019;40:3-35.

[7] Jolley D, Douglas KM. The effects of anti-vaccine conspiracy theories on vaccination $\begin{array}{lll}\text { intentions. } & \text { PLoS 2014;9(2):e89177. }\end{array}$ https://journals.plos.org/plosone/article?id=10.1371/journal.pone.0089177

${ }^{[8]}$ Imhoff R, Lamberty P, Klein O. Using power as a negative cue: How conspiracy mentality affects epistemic trust in sources of historical knowledge. 2018;44(9):1364-1379.

[9] Jaspal R, Lopes R. Psychological wellbeing facilitates accurate HIV risk appraisal in gay and bisexual men. Sexual Health. 2020;17(3):288-295. 
[10] Amirkhanian YA. Social networks, sexual networks and HIV risk in men who have sex with men. Current HIV/AIDS Reports. 2014;11:81-92.

[11] Jaspal R. Enhancing Sexual Health, Self-Identity and Wellbeing among Men Who Have Sex With Men: A Guide for Practitioners. London: Jessica Kingsley Publishers; 2018.

${ }^{[12]}$ MacKellar DA, Valleroy LA, Secura, GM, et al. Perceptions of lifetime risk and actual risk for acquiring HIV among young men who have sex with men. AIDS Behav;11(2):263-270.

${ }^{[13]}$ Frye V, Nandi V, Egan J, et al. Sexual orientation- and race-based discrimination and sexual HIV risk behavior among urban MSM. AIDS and Behavior. 2015;19:257-269.

${ }^{[14]}$ Chard AN, Finneran C, Sullivan PS, Stephenson R. Experiences of homophobia among gay and bisexual men: results from a cross-sectional study in seven countries. Cult Health Sex. 2016;17(10):1174-1189.

${ }^{[15]}$ Fingerhut AW, Abdou CM. The role of healthcare stereotype threat and social identity threat in LGB health disparities. Journal of Social Issues. 2017;73(3):493-507.

${ }^{[16]}$ Heller J. Rumors and Realities: Making sense of HIV/AIDS conspiracy narratives and contemporary legends. Am J Pubic Health. 2015;105(1):e43-e50.

[17] Bogart L, Thorburn S. Are HIV/AIDS conspiracy beliefs a barrier to HIV prevention among African Americans?. Journal of Acquired Immune Deficiency Syndromes. 2005;38(2):213-218.

${ }^{[18]}$ Bogart, L., Galvan, F., Wagner, G., Klein, D. Longitudinal Association of HIV Conspiracy Beliefs with Sexual Risk Among Black Males Living with HIV. AIDS and Behavior. 2011;15:1180-1186

[19] Gaston GB, Alleyne-Green, B. The impact of African Americans' beliefs about HIV medical care on treatment adherence: A systematic review and recommendations for interventions. AIDS and Behavior. 2012;17:31-40.

${ }^{[20]}$ Bogart L M, Wagner G, Galvan F H, Banks D. Conspiracy beliefs about HIV are related to antiretroviral treatment nonadherence among African American men with HIV. J Acquir Immune Defic Syndr. 2010;53(5):648-55.

${ }^{[21]}$ Gillman J, Davila J, Sansgiry S, et al. The effect of conspiracy beliefs and trust on HIV diagnosis, linkage, and retention in young MSM with HIV. Journal of Health Care for the Poor and Underserved. 2013;24(1):36-45.

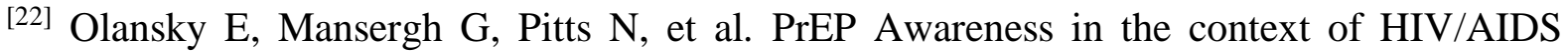
conspiracy beliefs among Black/African American and Hispanic/Latino MSM in three urban US cities. J Homosex. 2019;11:1-11.

${ }^{[23]}$ Brooks R A, Allen V C, Regan R, et al. HIV/AIDS conspiracy beliefs and intention to adopt preexposure prophylaxis among black men who have sex with men in Los Angeles. International Journal of STD \& AIDS. 2017;29(4):375-381.

${ }^{[24]}$ Peng P, Su S, Fairley CK, et al. A global estimate of the acceptability of pre-exposure prophylaxis for HIV among men who have sex with men: A systematic review and metaanalysis. AIDS Behav. 2018;22(4):1063-74.

${ }^{[25]}$ Bull L, Dimitrijevic P, Beverley S, et al. Perceived need of, and interest in, HIV preexposure prophylaxis amongst men who have sex with men attending three sexual health clinics in London, UK. Int J STD AIDS. 2017;29(5):435-442.

[26] Jaspal R, Lopes B, Bayley J, Papaloukas P. A structural equation model to predict the acceptability of pre-exposure prophylaxis in men who have sex with men in Leicester, UK. HIV Medicine. 2018;20(1):11-18.

${ }^{[27]}$ Zhou F, Gao L, Li S, et al. Willingness to accept HIV pre-exposure prophylaxis among Chinese men who have sex with men. PLOS ONE. 2012;7(3):e32329.

${ }^{[28]}$ Dolling DI, Desai M, McOwan A, et al. An analysis of baseline data from the PROUD study: an open-label randomised trial of pre-exposure prophylaxis. 2016;17:163. 
${ }^{[29]}$ Eaton LA, Driffin DD, Kegler C, et al. The role of stigma and medical mistrust in the routine health care engagement of Black men who have sex with men. American Journal of Public Health. 2015;105(2):e75-e83.

[30] Kaiser R, Major B. A social psychological perspective on perceiving and reporting discrimination. Law \& Social Inquiry. 2006;31(4):801-830.

[31] Abalakina-Paap M, Stephan WG, Craig T, Gregory, WL. Belief in conspiracies. Political Psychology. 2002;20(3):637-47.

${ }^{[32]}$ Parsons, S., Simmons, W., Shinhoster, F., Kilburn, J. A test of the grapevine: An empirical examination of the conspiracy theories among African Americans. Sociological Spectrum. 1999;19(2):201-222.

${ }^{[33]}$ Simmons, W. P., Parsons, S. Beliefs in conspiracy theories among African Americans: A comparison of elites and masses. Social Science Quarterly. 2005;86(3):582-598.

[34] Schönbrodt, FD, Perugini, M. At what sample size do correlations stabilize? Journal of Research in Personality. 2013;47(5):609-612.

${ }^{[35]}$ Sternthal MJ, Slopen N, Williams DR. Racial disparities in health: How much does stress really matter?. 2011;8(1):95-113.

[36] Bernstein RE, Delker BC, Knight JA, Freyd JJ. Hypervigilance in college students: Associations with betrayal and dissociation and psychometric properties in a Brief Hypervigilance Scale. Psychological Trauma: Theory, Research, Practice, \& Policy. 2015;7:448-445.

[37] Lantian A, Muller D, Nurra C, Douglas KM. Measuring belief in conspiracy theories: Validation of a French and English single-item scale. International Review of Social Psychology. 2016;29(1):1-14.

[38] Jaspal R, Lopes B, Maatouk I. The Attitudes toward Pre-Exposure Prophlyaxis (PrEP) Scale: Development \& validation. Journal of HIV/AIDS \& Social Services. 2019;18(2):197205.

${ }^{[39]}$ Reimer NK, Becker JC, Benz A, et al. Intergroup contact and social change: Implications of negative and positive contact for collective action in advantaged and disadvantaged groups. Personality and Social Psychology Bulletin. 2016;43(1):121-136.

${ }^{[40]}$ Nunnally, JC. Psychometric theory (2nd ed.). McGraw-Hill. 1978.

${ }^{[41]}$ Hayes AF. Methodology in the social sciences. Introduction to mediation, moderation, and conditional process analysis: A regression-based approach. Guilford Press. 2013.

${ }^{[42]}$ Pettifor A, Lippman SA, Selin, AM, et al. A cluster randomized-controlled trial of a community mobilization intervention to change gender norms and reduce HIV risk in rural South Africa: study design and intervention. BMC Public Health. 2015;15:752.

${ }^{[43]}$ Hankins CA, Zalduondo BO. Combination prevention: a deeper understanding of effective HIV prevention. AIDS. 2010;24:s70-s80.

${ }^{[44]}$ Tavoschi L, Gomes Dias J, Pharris A. New HIV diagnoses among adults aged 50 years or older in 31 European countries, 2004-15: an analysis of surveillance data. The Lancet. 2017;4(11):PE514-E521.

${ }^{[45]}$ Hampton MC, Halkitis PN, Storhom ER, et al. Sexual risk taking in relation to sexual identification, age, and education in a diverse sample of African American men who have sex with men (MSM) in New York City. AIDS and Behavior. 2012;17:931-938.

${ }^{[46]}$ Holt M, Lea T, Bear B, Halliday D, Ellard J, Murphy D, Kolstee J, Wit J. Trends in Attitudes to and the Use of HIV Pre-exposure Prophylaxis by Australian Gay and Bisexual Men, 20112017: Implications for Further Implementation from a Diffusion of Innovations Perspective. AIDS and Behavior. 2019; 23:1939-1950. 
Table 1: Means and Pearson product-moment correlations between all measured variables.

\begin{tabular}{|c|c|c|c|c|c|c|c|c|c|c|}
\hline & $\begin{array}{c}\mathrm{M} \\
(S D) \\
\end{array}$ & 1 & 2 & 3 & 4 & 5 & 6 & 7 & 8 & 9 \\
\hline (1) HIV conspiracy beliefs & $\begin{array}{c}1.45^{+} \\
(0.71)\end{array}$ & - & $\begin{array}{c}.37 * * * \\
{[0.257 \text { / }} \\
0.494]\end{array}$ & $\begin{array}{c}.33 * * * \\
{[0.195 /} \\
0.461]\end{array}$ & $\begin{array}{c}.24 * * * \\
{[0.128 /} \\
0.349]\end{array}$ & $\begin{array}{c}.28 * * * \\
{[0.109 /} \\
0.433]\end{array}$ & $\begin{array}{c}-.15^{¥} \\
{[-0.321 /} \\
0.019]\end{array}$ & $\begin{array}{c}-.22 * * * \\
{[-0.341 /} \\
-0.100]\end{array}$ & $\begin{array}{c}.00 \\
{[-0.120 /} \\
0.110]\end{array}$ & $\begin{array}{c}-.29 * * * \\
{[-0.405 /} \\
-0.172]\end{array}$ \\
\hline (2) General conspiracy theorising & $\begin{array}{c}3.67 \\
(1.63)\end{array}$ & & - & $\begin{array}{c}.22 * * \\
{[0.095 /} \\
0.327]\end{array}$ & $\begin{array}{c}.13^{*} \\
{[0.008 /} \\
0.247]\end{array}$ & $\begin{array}{c}.10 \quad[- \\
0.030 / \\
0.231]\end{array}$ & $\begin{array}{c}-.16^{*} \\
{[-0.316 /} \\
-0.007]\end{array}$ & $\begin{array}{c}-.08 \\
{[-0.213 /} \\
0.051]\end{array}$ & $\begin{array}{c}-.11 \\
{[-0.227 /} \\
0.014]\end{array}$ & $\begin{array}{c}-.19 * * \\
{[-0.313 /} \\
-0.078]\end{array}$ \\
\hline (3) Discrimination & $\begin{array}{c}2.16 \\
(1.14)\end{array}$ & & & - & $\begin{array}{c}.44 * * * \\
{[0.340 /} \\
0.543]\end{array}$ & $\begin{array}{c}.42 * * * \\
{[0.273 /} \\
0.567]\end{array}$ & $\begin{array}{c}-.07 \\
{[-0.220 /} \\
0.082]\end{array}$ & $\begin{array}{c}-.02 \\
{[-0.139 /} \\
0.104]\end{array}$ & $\begin{array}{c}-11 \\
{[-0.206 /} \\
-0.004]\end{array}$ & $\begin{array}{c}-.08 \\
{[-0.200 /} \\
0.031]\end{array}$ \\
\hline (4) Hyperviligance & $\begin{array}{c}2.16 \\
(0.97)\end{array}$ & & & & - & $\begin{array}{c}.26 * * \\
{[0.128 /} \\
0.397]\end{array}$ & $\begin{array}{c}-.20 * \\
{[-0.365 /} \\
-0.049]\end{array}$ & $\begin{array}{c}-.04 \\
{[-0.181 /} \\
0.102]\end{array}$ & $\begin{array}{c}-.31 * * * \\
{[-0.416 /} \\
-0.189]\end{array}$ & $\begin{array}{c}-.17 * * \\
{[-0.307 /} \\
-0.037]\end{array}$ \\
\hline (5) Negative contact $(n=162)$ & $\begin{array}{c}1.90 \\
(1.17)\end{array}$ & & & & & & $\begin{array}{c}-.37 * * * \\
{[-0.508 /} \\
-0.237]\end{array}$ & $\begin{array}{c}-.02 \\
{[-0.157 /} \\
0110]\end{array}$ & $\begin{array}{c}-.13 \\
{[-0.266 /} \\
-0.076]\end{array}$ & $\begin{array}{c}-.07 \\
{[-0.228 /} \\
0.085]\end{array}$ \\
\hline (6) Positive contact $(n=162)$ & $\begin{array}{c}5.12 \\
(1.22)\end{array}$ & & & & & & - & $\begin{array}{c}.20^{*} \\
{[0.050 /} \\
0.342]\end{array}$ & $\begin{array}{c}.06 \\
{[-0.095 /} \\
.0219]\end{array}$ & $\begin{array}{c}-.01 \\
{[-0.163 /} \\
0.147]\end{array}$ \\
\hline (7) PrEP attitudes & $\begin{array}{c}4.80 \\
(0.78)\end{array}$ & & & & & & & - & $\begin{array}{c}-.18 * * \\
{[-0.303 /} \\
-0.061]\end{array}$ & $\begin{array}{c}.12^{¥}[- \\
0.008 /- \\
0.254]\end{array}$ \\
\hline (8) Age & $\begin{array}{c}34.35 \\
(12.04)\end{array}$ & & & & & & & & - & $\begin{array}{c}-.04 \\
{[-0.164 /} \\
0.081]\end{array}$ \\
\hline (9) Education & $\begin{array}{c}5.18 \\
(1.38)\end{array}$ & & & & & & & & & - \\
\hline
\end{tabular}


Table 2. Three hierarchical regression models predicting HIV conspiracy beliefs, general conspiracy theorizing, and attitudes towards PrEP with experiences of discrimination, respectively $(N=244)$.

\section{Variables Explained}

\begin{tabular}{|c|c|c|c|c|c|c|c|c|}
\hline \multirow{2}{*}{\multicolumn{2}{|c|}{ Predictors }} & \multicolumn{2}{|c|}{ HIV conspiracy } & \multicolumn{2}{|c|}{ General conspiracy } & \multicolumn{3}{|c|}{ Attitudes towards PrEP } \\
\hline & & Step 1 & Step 2 & Step 1 & Step 2 & Step 1 & Step 2 & Step 3 \\
\hline \multirow[t]{2}{*}{1} & Age & -.01 & .02 & $-.12^{¥}$ & -.10 & $.18 * *$ & $-.18 * *$ & $-18 * *$ \\
\hline & & $\begin{array}{c}{[-0.002 /} \\
0.001]\end{array}$ & $\begin{array}{c}{[-0.001 /} \\
0.002]\end{array}$ & $\begin{array}{c}{[-0.033 /} \\
0.001]\end{array}$ & $\begin{array}{c}{[-0.030 /} \\
0.004]\end{array}$ & $\begin{array}{c}{[-0.020 /} \\
-0.003]\end{array}$ & $\begin{array}{c}{[-0.020 /} \\
-0.004]\end{array}$ & $\begin{array}{c}{[-0.020 /-} \\
0.004]\end{array}$ \\
\hline \multirow[t]{2}{*}{1} & Education & $-.29 * * *$ & $-.26 * * *$ & $-.20 *$ & $-.18 *$ & $.11^{¥}$ & $.11^{¥}$ & .05 \\
\hline & & $\begin{array}{c}{[-0.048 /-} \\
0.019]\end{array}$ & $\begin{array}{c}{[-0.044 /} \\
-0.017]\end{array}$ & $\begin{array}{c}{[-0.380 /} \\
-0.088]\end{array}$ & $\begin{array}{c}{[-0.359 /} \\
0.071]\end{array}$ & $\begin{array}{c}{[-0.006 /} \\
0.136]\end{array}$ & $\begin{array}{c}{[-0.007 /} \\
0.135]\end{array}$ & $\begin{array}{c}{[-0.044 /} \\
0.103]\end{array}$ \\
\hline \multirow[t]{2}{*}{2} & Discrimination & - & $.31 * * *$ & - & $.19 *$ & - & -.03 & .04 \\
\hline & & & $\begin{array}{c}{[0.027 /} \\
0.060]\end{array}$ & & $\begin{array}{c}{[0.100 /} \\
0.453]\end{array}$ & & $\begin{array}{c}{[-0.106 /} \\
0.068]\end{array}$ & $\begin{array}{c}{[-0.061 /} \\
0.120]\end{array}$ \\
\hline 3 & HIV conspiracy & - & - & - & - & - & - & $\begin{array}{c}-.21 * * \\
{[-1.749 /-} \\
0.355]\end{array}$ \\
\hline \multirow[t]{3}{*}{3} & General conspiracy & - & - & - & - & - & - & $\begin{array}{c}-.02 \\
{[-0.075 /} \\
0.054]\end{array}$ \\
\hline & $R^{2}$ & .29 & .42 & .23 & .30 & .22 & .22 & .30 \\
\hline & $R^{2}$ change & & $.09 * * *$ & & $.04 *$ & & .00 & $.04 * *$ \\
\hline
\end{tabular}

Notes. ${ }^{¥} p<.10 . * p<.05 . * * p<.01 . * * * p<.001$. Squared brackets present $95 \%$ confidence intervals. 
Table 3. Three hierarchical regression models predicting HIV conspiracy beliefs, general conspiracy theorising and attitudes towards PrEP with contact experiences in a sexual health screening, respectively $(N=244)$.

\section{Variables Explained}

HIV conspiracy $\quad$ General CT $\quad$ Attitudes towards PrEP

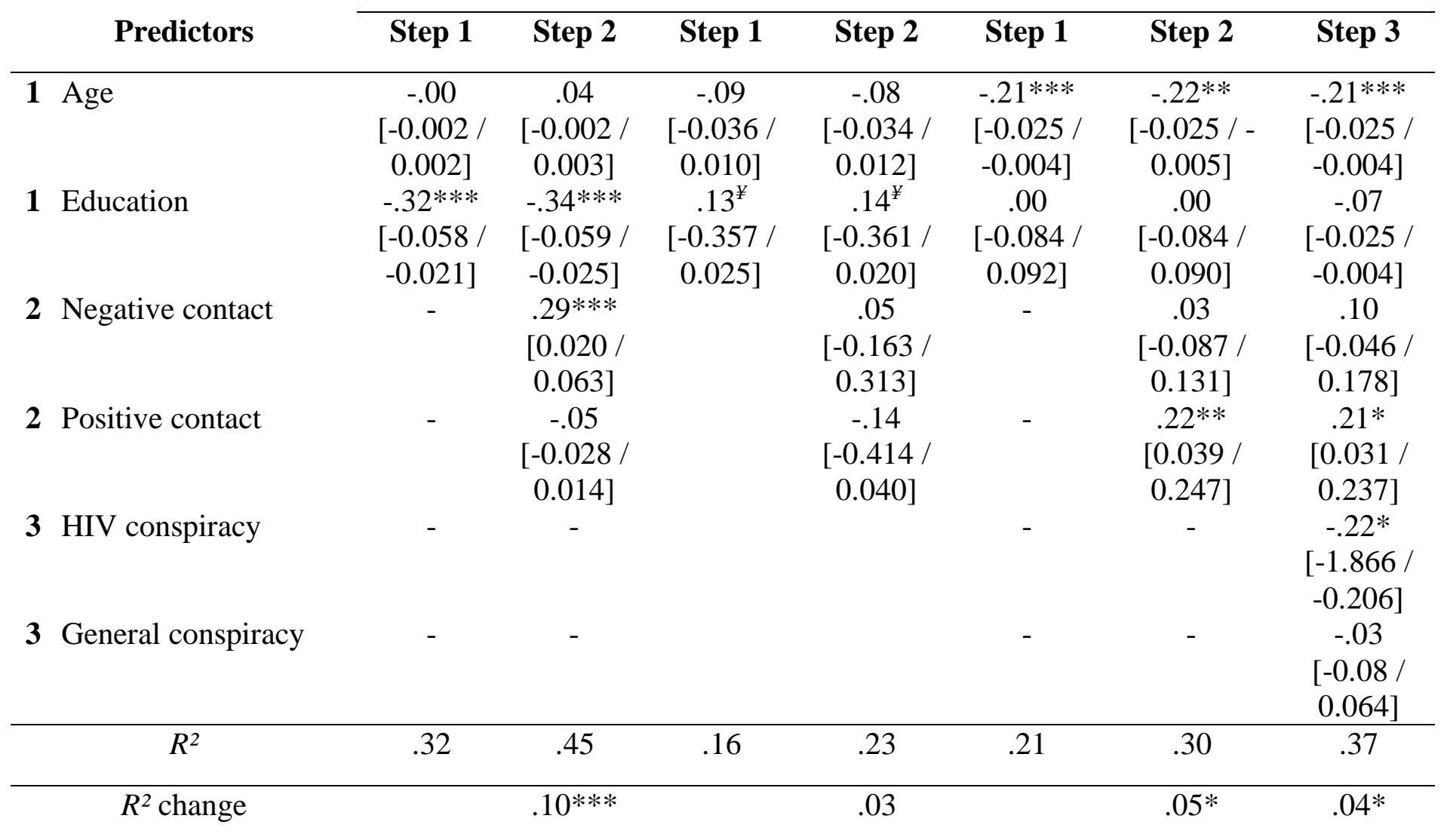

Notes. ${ }^{¥} p<.10 . * p<.05 . * * p<.01 . * * * p<.001$. Squared brackets present $95 \%$ confidence intervals. 


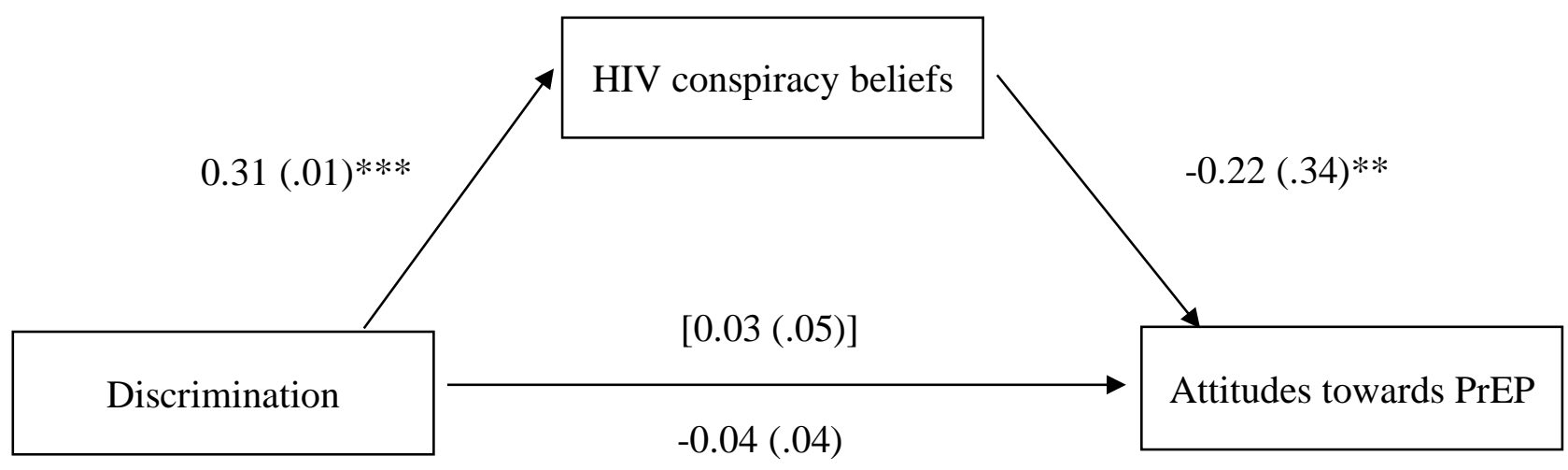

$R^{2}=.05, F(3,240)=3.92, p=.009$

Figure 1. Mediation model showing that discrimination is associated with HIV conspiracy beliefs, which in turn, is associated with attitudes towards $\operatorname{PrEP}(N=244$, controlling for age and education).

Note. Path estimates represent standardized coefficients. Standard errors presented in parentheses. Notes. $* * p<.01 . * * * p<.001$. 


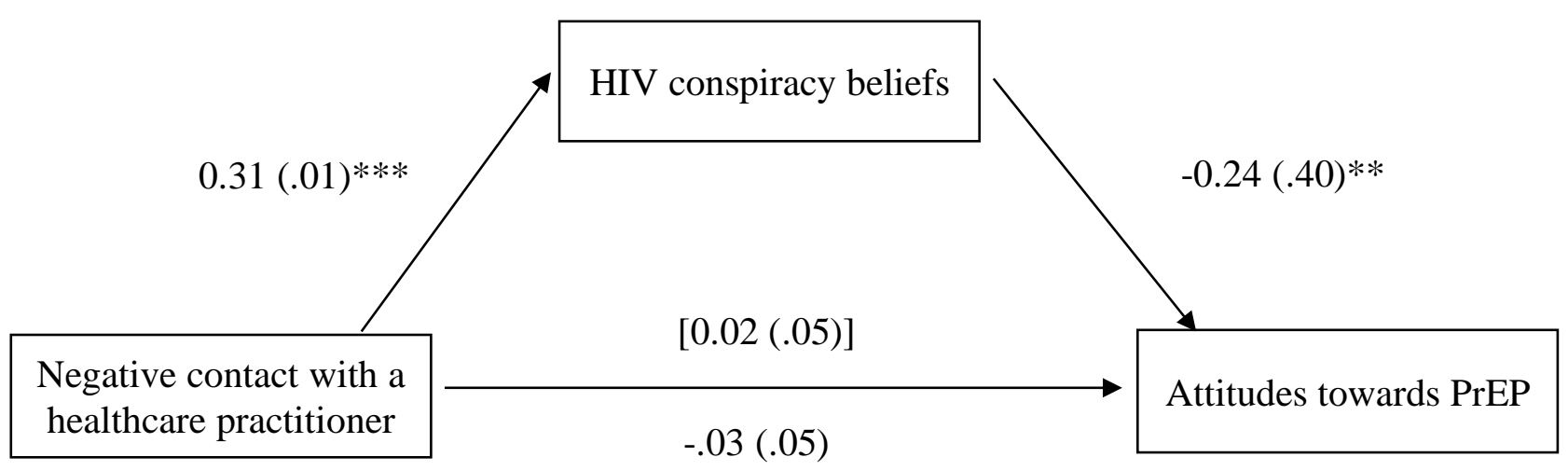

$R^{2}=.05, F(3,158)=2.59, p=.050$

Figure 2. Mediation model showing that negative contact with health care professionals is associated with HIV conspiracy beliefs, which in turn, is associated with attitudes towards $\operatorname{PrEP}(N=162$, controlling for age and education).

Note. Path estimates represent standardized coefficients. Standard errors presented in parentheses. Notes. $* * p<.01 . * * * p<.001$. 


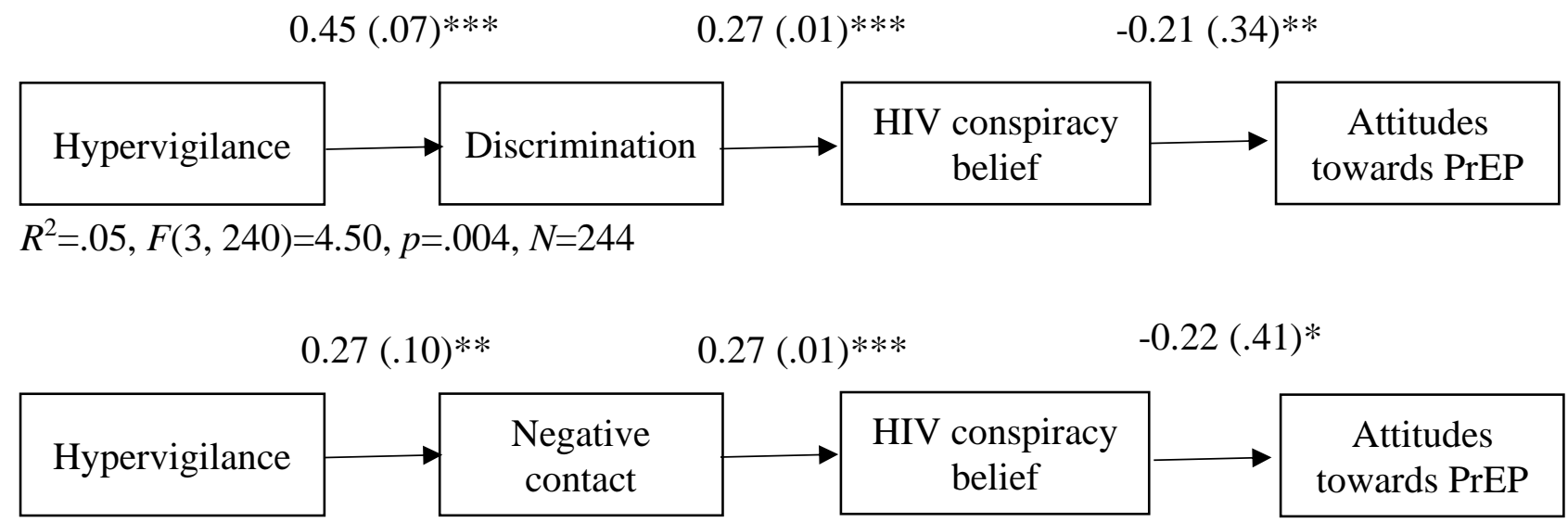

$R^{2}=.06, F(3,158)=3.30, p=.022, n=162$

Figure 3. Serial mediation models demonstrating that hypervigilance is associated with discrimination (and negative contact, respectively), which in turn, is associated with conspiracy belief and attitudes towards PrEP (controlling for age and education).

Note. Path estimates represent standardized coefficients. Standard errors presented in parentheses. Notes. $* p<.05 . * * p<.01 . * * * p<.001$. 